\title{
Is Physical Activity Good or Bad for the Female Pelvic Floor? A Narrative Review
}

\author{
Kari B $\emptyset^{1,2}\left(\mathbb{D} \cdot\right.$ Ingrid Elisabeth Nygaard ${ }^{3}$
}

Published online: 9 December 2019

(c) The Author(s) 2019

\begin{abstract}
More women participate in sports than ever before and the proportion of women athletes at the Olympic Games is nearly $50 \%$. The pelvic floor in women may be the only area of the body where the positive effect of physical activity has been questioned. The aim of this narrative review is to present two widely held opposing hypotheses on the effect of general exercise on the pelvic floor and to discuss the evidence for each. Hypothesis 1: by strengthening the pelvic floor muscles (PFM) and decreasing the levator hiatus, exercise decreases the risk of urinary incontinence, anal incontinence and pelvic organ prolapse, but negatively affects the ease and safety of childbirth. Hypothesis 2: by overloading and stretching the PFM, exercise not only increases the risk of these disorders, but also makes labor and childbirth easier, as the PFM do not obstruct the exit of the fetus. Key findings of this review endorse aspects of both hypotheses. Exercising women generally have similar or stronger PFM strength and larger levator ani muscles than non-exercising women, but this does not seem to have a greater risk of obstructed labor or childbirth. Additionally, women that specifically train their PFM while pregnant are not more likely to have outcomes associated with obstructed labor. Mild-to-moderate physical activity, such as walking, decreases the risk of urinary incontinence but female athletes are about three times more likely to have urinary incontinence compared to controls. There is some evidence that strenuous exercise may cause and worsen pelvic organ prolapse, but data are inconsistent. Both intra-abdominal pressure associated with exercise and PFM strength vary between activities and between women; thus the threshold for optimal or negative effects on the pelvic floor almost certainly differs from person to person. Our review highlights many knowledge gaps that need to be understood to understand the full effects of strenuous and non-strenuous activities on pelvic floor health.
\end{abstract}

\section{Introduction}

Regular physical activity, that is, "any bodily movement produced by the skeletal muscles that results in a substantial increase over the resting energy expenditure" [1], is an important and modifiable health factor for all age groups, and there is evidence that "exercise is medicine" for a wide range of diseases and conditions [2]. In contrast to physical activity, which can be performed in varying domains, exercise training is a form of physical activity "usually

Kari $\mathrm{B} \varnothing$

kari.bo@nih.no

1 Department of Sports Medicine, Norwegian School of Sport Sciences, PB 4014, Ullevål Stadion, 0806 Oslo, Norway

2 Akershus University Hospital, Lørenskog, Norway

3 Division of Female Pelvic Medicine and Reconstructive Surgery, Department of Obstetrics and Gynecology, University of Utah School of Medicine, Salt Lake City, USA

\section{Key Points}

Exercising women have three times the risk of experiencing urinary incontinence.

Exercising women have larger cross-sectional area of the pelvic floor muscles but wider levator hiatus.

General exercise and pelvic floor muscle training during pregnancy have no negative effect on length of labor or mode of delivery.

Knowledge gaps prohibit firm conclusions about the role of strenuous physical activity in the incidence of pelvic floor disorders and highlight the need for further highquality research.

performed on a repeated basis over an extended period of time with a specific external objective such as improvement of fitness, physical performance or health" [1]. The 
2018 Physical Activity Guidelines Advisory Committee Report concluded that health benefits of regular physical activity include reduced risk of excessive weight gain, improved cognitive function, reduced risk of dementia and reduced risk of cancers in various sites [3]. In addition, physical activity reduces the risk of progression of some chronic conditions, such as osteoarthritis, hypertension, and type 2 diabetes. Hence, staying physically active throughout the lifespan is of great importance for health and well being.

This message is clearly heard by women, as more and more participate in sports than ever before and the proportion of women athletes at the most recent Olympic Games was nearly $50 \%$. Women and men differ in key areas of anatomy and physiology relevant to sports training, but perhaps of greatest difference is the often over-looked pelvic floor.

Indeed, the pelvic floor in women may be the only area of the body where the positive effect of physical activity has been questioned. The pelvic floor consists of muscles and connective tissues (ligaments and fascia) that need to work together to form a structural support for the pelvic organs to prevent urinary leakage or protrusion of the pelvic organs. Pelvic floor dysfunction may lead to common conditions such as urinary incontinence (UI), anal incontinence (AI) and pelvic organ prolapse (POP) [4]. Given that these conditions affect between one in three to one in four women $[5,6]$, understanding whether physical exercise might predispose to, or prevent, dysfunction of the pelvic floor, and thus these conditions, is important. Additionally, the conditions themselves, especially UI, may cause women to stop exercising or be one of many barriers to continuing lifelong regular physical activity $[7,8]$. As a consequence, women and society bear the cost of inactivity and UI, both substantial $[9,10]$.

Known risk factors for pelvic floor disorders are pregnancy and vaginal childbirth, older age and obesity [11]. Strenuous work or exercise has also been widely debated as a possible risk factor. Indeed, the very definition of stress urinary incontinence [SUI], "complaint of involuntary loss of urine during effort or physical exertion, or during sneezing or coughing" [12], highlights the fact that leakage occurs during physical activity. Adequate function of the pelvic floor including the pelvic floor muscles (PFM), connective tissue and nervous system, is crucial in counteracting the increases in intra-abdominal pressure (IAP) and ground reaction forces that occur during physical activity, and well-functioning PFM may compensate for weak connective tissue.

In 2004, B $\varnothing$ described two possible and opposing hypotheses on the effect of physical activity on the pelvic floor [13]:
1.General exercise training strengthens the pelvic floor. The theories behind this hypothesis are that the impacts that occur during physical activity may stretch and fatigue the PFM, leading to a training effect, and/or that impacts during exercise could lead to a co-contraction of the PFM, creating an acute indirect training effect. This may reduce the levator hiatus area by causing hypertrophy and shortening of the surrounding muscles, thereby lifting the pelvic floor and the internal organs into a higher pelvic location. Theoretically, such morphological changes could reduce the risk of UI, AI and POP. On the other hand, it is also theoretically possible that these changes could negatively impact labor and childbirth by making it more difficult for the fetus to descend with pushing.

2.General exercise training overloads, stretches and weakens the pelvic floor. This hypothesis is based on the fact that physical activity increases IAP, and if the pelvic floor muscles are not able to co-contract quickly or strongly enough to counteract this increased pressure or withstand the ground reaction forces, the levator hiatus could become wider, stretching and weakening the muscles. According to this theory, overload of the PFM may increase the risk of UI, AI and POP, but on the other hand, should also result in easier childbirth.

The aim of this narrative literature review is to describe and discuss the evidence supporting or refuting these two hypotheses, including how exercise influences PFM strength, muscle fatigue, pelvic floor morphology, pelvic floor disorders, and labor and birth variables.

\section{Methodological Considerations}

We based our paper on previous review articles in this area and articles from the reference lists of these articles [13-20] and on an updated search on February 2019. The search strategy in PubMed included the terms: (prevalence OR incidence) AND ("stress urinary incontinence" OR "urinary incontinence" OR "urine incontinence" OR "fecal incontinence" OR "faecal incontinence" OR "pelvic organ prolapse") AND (athletes OR athlete OR exercisers OR sport [tw] OR sports [tw]; $N=66$ and (exercise OR "physical activity") AND ("intra-abdominal pressure" OR "intraabdominal pressure" OR "abdominal pressure") AND "pelvic floor"; $N=52$. Of these 118 studies, 23 and 35, respectively, did not address the areas of interest, and 20 studies were represented in both searches, leaving 40 published studies from PubMed for review, in addition to the review manuscripts. We also included seven manuscripts not found in our search to incorporate papers we were aware are not included in the PubMed database. 


\section{Findings}

\subsection{How Do Specific Exercises Influence Intra-Abdominal Pressure?}

IAP changes throughout the course of the day, increasing with position changes, movement, breathing, and abdominal wall contraction. Two exercise modalities may increase IAP to a greater extent than others and thus possibly affect the pelvic floor: strenuous strength training, such as weight and power lifting, and high-impact activities, such as jumping and running. Strength training and weight lifting are characterized by short-duration bursts of impact with possible high increases in IAP, but low ground reaction forces [15]. High-impact activities are associated with a high number of impacts from both ground reaction forces and (probably smaller) increases of IAP. Continent women automatically pre- or co-contract the PFM before and during impact activities and are not aware of this automatic function [21]. Women with SUI can learn to voluntarily pre- and co-contract the PFM when coughing [22]. This would in theory also be possible during some strength-training exercises or heavy lifting of short duration, but this has not yet been investigated. However, in long-lasting activities with repeated impacts close together in time, such as running or high-impact aerobics, it would be impossible for women to perform voluntary PFM contractions for each step or movement.

To have an understanding of the forces the pelvic floor must withstand, it is useful to consider these forces during propagation. Hay [23] estimated maximum vertical ground reaction forces during different activities and reported those during running to be 3-4 times the body weight, jumping, 5-12 times, landing from a front somersault, 9 times, landing from double back somersault, 14 times, and long-jump, 16 times. Since then, many authors have investigated vertical ground reaction forces and confirmed substantial forces that occur during running, walking and jumping. While out of the scope of the current review, it is instructive to summarize one example. Seegmiller et al. studied ground reaction forces in drop landings, which produce a characteristic two-peak curve, in ten competitive gymnasts [24]. Scaling the force data to $\mathrm{N} / \mathrm{kg}$ to account for differences in body mass among subjects, they reported that the first peak vertical force magnitudes ranged from $9.5 \mathrm{~N} / \mathrm{kg}$ at $30-\mathrm{cm}$ height to $32.8 \mathrm{~N} / \mathrm{kg}$ at $90-\mathrm{cm}$ height, while the second much greater peak vertical force magnitudes ranged from 27.1 at 30-cm height to $56.0 \mathrm{~N} /$ $\mathrm{kg}$ at $90 \mathrm{~cm}$. While most women are unlikely to experience these types of loads on the pelvic floor, artistic gymnasts may do so during the landing phases of many of their routines.

Measuring pressures in the bladder, rectum, or upper vagina provides a closer approximation of the forces experienced by the pelvic floor, although discounting acceleration forces. James was one of the first to measure bladder pressures during physical activity, using an air-filled balloon in the bladder [25]. Recorded pressures during coughing, jumping and running and bending over to the floor were 125, 90 and $20 \mathrm{cmH}_{2} \mathrm{O}$, respectively.

Subsequent studies demonstrate clearly that maximal IAP values have a very wide range amongst women doing the same standardized activity [26]. In addition, maximal IAPs vary across studies for the same activity, in part related to the instrumentation with which IAP is measured and how maximal IAP is constructed, as well as to differences between populations [27, 28]. Breathing pattern is generally not standardized, which can also influence IAP [29]. IAPs across studies also vary because both total (that is, maximal IAP from atmospheric pressure baseline) and net (difference between maximal IAP and a baseline value, usually standing) are used to operationalize IAP but usually not specified in reports.

Examples of IAPs during dynamic activities and abdominal training are summarized in Tables 1 and 2. In an interesting study challenging the widely held belief that pelvic floor "safe" exercises generate lower IAPs than corresponding conventional exercises, no differences in IAPs were found between the recommended and discouraged versions of half the exercises, including ball rotations, lunges, core, push-ups and squats [30]. Others have also pointed out that activities generally restricted after surgery may generate lower IAPs than unrestricted activities. For example, mean maximal IAP was greater with standing up from a chair than it was for abdominal crunches, climbing stairs, sit-ups and many lifting activities [31]. Similarly, lifting $20 \mathrm{lbs}$ generated less IAP than standing up from a chair [32]. Coughing generates higher IAP than most exercises (Table 1).

In a study using a novel intra-vaginal pressure sensor that simultaneously measures PFM contraction and IAP during a selection of supine exercises in 21 women's health physiotherapists, the mean vaginal pressure during a PFM contraction increased $16.3 \mathrm{mmHg}$ (SD 12.3) while the corresponding IAP increase was minimal [mean $3.4 \mathrm{mmHg}$ (SD 2.2)] [33]. During an abdominal crunch, the IAP increased $8.3 \mathrm{mmHg}$ (SD 7.3); simultaneously the pressure measured at level of the PFM also increased, indicating co-contraction, to half that of the PFM contraction [mean $8.2 \mathrm{mmHg}$ (SD 8.0)].

\subsection{Does General Exercise Strengthen or Weaken the Pelvic Floor Muscles?}

\subsubsection{Does One Bout of Strenuous Exercise Fatigue the PFM?}

We found only two studies measuring the acute effect of one bout of exercise. In a short-term experimental crossover study of young nulliparous women with symptoms of 
Table 1 Examples of mean maximal intra-abdominal pressures generated during dynamic activities ${ }^{\mathrm{a}}$

\begin{tabular}{|c|c|c|c|c|c|}
\hline Study & $N$ & Walking & Jumping & Running & Coughing \\
\hline Weir et al. [31] (2006) & $30^{\mathrm{b}}$ & $\begin{array}{l}\text { Treadmill, } 3.3 \mathrm{mph} \\
79.0(48-190) \mathrm{cmH}_{2} \mathrm{O}\end{array}$ & $\begin{array}{l}\text { Jumping jacks } \\
127(59-190) \mathrm{cmH}_{2} \mathrm{O}\end{array}$ & & \\
\hline $\begin{array}{l}\text { O’Dell and Morse [106] } \\
\text { (2007) }\end{array}$ & 12 & & & $\begin{array}{l}\text { Jogging in place } \\
54(27-76) \mathrm{cmH}_{2} \mathrm{O}\end{array}$ & $98(50-131) \mathrm{cmH}_{2} \mathrm{O}$ \\
\hline $\begin{array}{l}\text { Kruger et al. [107] } \\
\text { (2013) }\end{array}$ & 12 & $\begin{array}{l}\text { Treadmill, } 6 \mathrm{~km} / \mathrm{h} \\
38 \text { (N/A) } \mathrm{cmH}_{2} \mathrm{O}\end{array}$ & $\begin{array}{l}\text { Star jumps } \\
53 \text { (NA) } \mathrm{cmH}_{2} \mathrm{O}\end{array}$ & $\begin{array}{l}\text { On treadmill } \\
7 \mathrm{~km} / \mathrm{h} 45 \text { (NA) } \mathrm{cmH}_{2} \mathrm{O}\end{array}$ & 73 (N/A) $\mathrm{cmH}_{2} \mathrm{O}$ \\
\hline Shaw et al. [108] (2014) & 57 & $\begin{array}{l}\text { Treadmill, } 4.8 \mathrm{~km} / \mathrm{h} \\
25(15-37) \mathrm{cmH}_{2} \mathrm{O}\end{array}$ & & $\begin{array}{l}\text { On treadmill } \\
8-9.7 \mathrm{~km} / \mathrm{h} \\
67(32-99) \mathrm{cmH}_{2} \mathrm{O}\end{array}$ & $91(38-200) \mathrm{cmH}_{2} \mathrm{O}$ \\
\hline $\begin{array}{l}\text { Yamasato et al. [32] } \\
\text { (2014) }\end{array}$ & 147 with POP/SUI & & & & $80(14-150) \mathrm{cmH}_{2} \mathrm{O}$ \\
\hline $\begin{array}{l}\text { Coleman et al. [109] } \\
\text { (2014) }\end{array}$ & 46 & $\begin{array}{l}\text { Running track } \\
43(14-79) \mathrm{cmH}_{2} \mathrm{O} \text { slow } \\
\text { pace to } 62(40-110) \\
\mathrm{cmH}_{2} \mathrm{O} \text { fast pace }\end{array}$ & & & \\
\hline $\begin{array}{l}\text { Simpson et al. [110] } \\
\text { (2016) }\end{array}$ & 30 with SUI/POP & & & & $78(14-84) \mathrm{cmH}_{2} \mathrm{O}$ \\
\hline $\begin{array}{l}\text { DeGennaro et al. [111] } \\
\text { (2017) }\end{array}$ & 25 & $\begin{array}{l}\text { Treadmill, } 3.4 \mathrm{mph} \text { at } \\
14 \% \text { grade } \\
69(46-102) \mathrm{cmH}_{2} \mathrm{O}\end{array}$ & $\begin{array}{l}\text { Jumping jacks } \\
124(78-189) \mathrm{cmH}_{2} \mathrm{O}\end{array}$ & & \\
\hline
\end{tabular}

$P O P$ pelvic organ prolapse, SUI stress urinary incontinence, N/A not applicable (no range provided)

${ }^{a}$ All pressures were measured using vaginal catheters/sensors with the exception of Weir et al. [31], who measured pressure using a rectal catheter

${ }^{\mathrm{b}}$ Unless otherwise specified, participants did not report incontinence

SUI, there was a $17 \%$ reduction of maximum voluntary PFM contraction after a 90-min session that included strenuous high-impact endurance and strength training, but no change in vaginal resting pressure or muscular endurance [34]. In contrast, immediately after one bout of strenuous exercise in women that habitually performed CrossFit and one bout of non-strenuous exercise in recreational controls, there was no change in maximum voluntary PFM contraction, but there was a decrease in vaginal resting pressure in both groups, as well as slightly worse vaginal support [35].

We are aware of no prospective studies following women from onset of exercise over months or years of training to evaluate the effect of exercise training on PFM strength.

\subsubsection{Do Exercisers have Stronger or Weaker PFM than Non-Exercisers?}

Some studies have compared PFM strength between exercising women and controls. These studies provide mixed evidence for answering the question of whether exercisers have stronger or weaker PFM than non-exercisers.

3.2.2.1 Evidence in Support of Stronger PFM Compared to 44 healthy women, 49 high-impact athletes had stronger PFM than these controls [36]. In a group of 41 women, PFM strength correlated with aerobic capacity and also with habitual physical activity measured by questionnaire [37]. Controlling for PFM training and other factors, primigravid women performing general exercise at 21 week gestation $\geq 3$ times per week had stronger and more enduring PFM than non-exercisers [38].

3.2.2.2 Evidence in Support of Weaker PFM Volley- and basketball players ( $n=10$ each) had significantly weaker PFM than non-exercising controls [39].

\subsubsection{Evidence Suggesting No Difference in PFM Strength}

In a study of 70 healthy women, PFM strength did not differ between those habitually engaged in CrossFit and controls [35]. Another study of 100 postmenopausal women reported no linear relation between physical activity and PFM strength after adjusting for other factors [40]. Similarly, there were no differences in PFM strength between 30 women with no clinical diagnosis of pelvic floor disorders who were Pilates practitioners and sedentary controls [41]. In a cross-sectional analysis of 203 primiparous women 1 year postpartum, there were no significant associations between PFM force and measures of strength and fitness, including grip strength, trunk flexor endurance duration, percent body fat, or self-reported physical activity [42]. Similarly, another cross-sectional study found no association between physical 
Table 2 Examples of mean maximal intra-abdominal pressures generated during abdominal exercise and lifting ${ }^{\mathrm{a}}$

\begin{tabular}{|c|c|c|c|c|}
\hline Study & $N$ & Abdominal exercise & Heavy lifting & Lighter lifting \\
\hline Mouritsen et al. [112] (2007) & $23^{\mathrm{b}}$ & & & $\begin{array}{l}\text { Lift } 5.0 \mathrm{~kg} \\
22.3(\mathrm{~N} / \mathrm{A}) \mathrm{cmH}_{2} \mathrm{O}\end{array}$ \\
\hline O'Dell and Morse [106] (2007) & 12 & & $\begin{array}{l}\text { Lift } 20.4 \mathrm{~kg} \\
71(51-120) \mathrm{cmH}_{2} \mathrm{O}\end{array}$ & \\
\hline Gerten et al. [113] (2008) & 41 & & $\begin{array}{l}\text { Lift } 15.0 \mathrm{~kg} \\
82(\mathrm{~N} / \mathrm{A}) \mathrm{cmH}_{2} \mathrm{O}\end{array}$ & $\begin{array}{l}\text { Lift } 2.5 \mathrm{~kg} \\
48(\mathrm{~N} / \mathrm{A}) \mathrm{cmH}_{2} \mathrm{O}\end{array}$ \\
\hline Shaw et al. [108] (2014) & 57 & $\begin{array}{l}\text { Curl-up: } 19(7-82) \mathrm{cm} \mathrm{H}_{2} \mathrm{O} \\
\text { Full sit up: } 60(14-129) \mathrm{cm} \mathrm{H}_{2} \mathrm{O}\end{array}$ & $\begin{array}{l}13.6 \mathrm{~kg} \\
35(17-63) \mathrm{cmH}_{2} \mathrm{O} \\
18.2 \mathrm{~kg} \\
48(14-120) \mathrm{cmH}_{2} \mathrm{O}\end{array}$ & \\
\hline Yamasato et al. [32] (2014) & 147 with SUI/POP & & & $\begin{array}{l}\text { Lift } 4.5 \mathrm{~kg} \\
12(2-38) \mathrm{cmH}_{2} \mathrm{O} \\
\text { Lift } 9 \mathrm{~kg} \\
19(5-64) \mathrm{cmH}_{2} \mathrm{O}\end{array}$ \\
\hline Coleman et al. [114] (2015) & 16 & $\begin{array}{l}\text { Plank: } 38(23-60) \mathrm{cmH}_{2} \mathrm{O} \\
\text { Roll-up on mat: } 51(33-76) \\
\quad \mathrm{cmH}_{2} \mathrm{O} \\
\text { Roll-up on Pilates reformer: } 50 \\
\quad(29-74) \mathrm{cmH}_{2} \mathrm{O}\end{array}$ & & \\
\hline Simpson et al. [110] (2016) & 30 with SUI/POP & Curl-up: $50(17-100) \mathrm{cmH}_{2} \mathrm{O}$ & & \\
\hline DeGennaro et al. [111] (2017) & 25 & $\begin{array}{l}\text { Curl-up: } 27(9-66) \mathrm{cmH}_{2} \mathrm{O} \\
\text { Full sit up: } 64(28-133) \mathrm{cmH}_{2} \mathrm{O} \\
\text { Plank: } 49(23-95) \mathrm{cmH}_{2} \mathrm{O}\end{array}$ & & \\
\hline Hsu et al. [115] (2017) & $\begin{array}{l}206 \\
6-10 \text { weeks postpartum }\end{array}$ & & $\begin{array}{l}\text { Lift } 12.5 \mathrm{~kg} \\
54(26-80) \mathrm{cmH}_{2} \mathrm{O}\end{array}$ & \\
\hline
\end{tabular}

POP pelvic organ prolapse, SUI stress urinary incontinence, $N / A$ not applicable (no range provided)

${ }^{a}$ All pressures were measured using vaginal catheters/sensors with the exception of Gerten et al. [113], who measured pressure using a rectal catheter

${ }^{\mathrm{b}}$ Unless otherwise specified, participants did not report incontinence

activity level, assessed by questionnaire, and vaginal resting pressure, PFM strength and endurance [43]. However, there was a weak positive association between physical activity level in continent women and a weak negative association in incontinent women [43].

\subsubsection{How Does Exercise Affect PFM Activity?}

Some researchers have used vaginal surface electromyography (EMG) to measure activity attributed to the PFM during various activities. In ten healthy women, vaginal surface EMG activity was higher during running at $11 \mathrm{~km} / \mathrm{h} \mathrm{com-}$ pared to 7 or $9 \mathrm{~km} / \mathrm{h}$ [44]. In another study of 16 healthy women, EMG activity during jumps occurring while drop landing and mini-trampolining was above that of the PFM onset threshold and pre- and co-contraction activity increased significantly with jumping height and body weight force [45]. A review of 28 studies about PFM activity during impact activities, concluded that the timing of PFM activity in relation to the activity of other trunk muscles appears to be important in maintaining continence and that women with SUI have delayed PFM activity during impact activities [46].

\subsection{What is the Effect of Exercise on Pelvic Floor Morphology?}

There were no differences in the size of the pelvis or urogenital hiatus on magnetic resonance imaging (MRI) in ten athletes versus ten age-matched controls, but the crosssectional area of the levator ani muscle was $20 \%$ higher in the athletes [47]. Using 3D/4D translabial ultrasound, 24 nulliparous high-impact athletes had a larger levator hiatus area on Valsalva, greater levator ani muscle diameter, and greater bladder descent during Valsalva than 25 age- and body mass index (BMI)-matched controls [48]. These results were somewhat contradicted by findings that five incontinent football players had significantly greater levator muscle thickness at the midvagina on MRI than seven continent players [49]. Another study found no difference in vaginal support between 35 women habitually engaged in CrossFit and controls [35]. In primiparas, there was no difference in levator hiatus area at 21 weeks gestation between women who reported exercising for 30 or more minutes at least three times per week and non-exercisers, but at 37 weeks, exercisers had significantly larger levator hiatus area both at rest 
and during Valsalva [38]. The proportion of women that reported also doing PFM training three or more times per week was similar between groups, about $15 \%$.

In a group of 90 women of whom $60 \%$ reported SUI and $25 \%$ were unable to contract the PFM, all displayed bladderbased depression on ultrasound when performing abdominal curls. Breathing pattern was not standardized. There were no differences between women with or without SUI, but parous women displayed significantly larger depression than nulliparous women [50].

\subsection{What is the Effect of Exercise on Urinary Incontinence?}

We identified no randomized controlled trials (RCTs) evaluating the effect of physical activity or general exercise training on UI that did not also include pelvic floor muscle training (PFMT). Numerous cross-sectional and fewer cohort studies have evaluated the association between exercise and UI

\subsubsection{Less Ul in Exercisers}

Mild-to-moderate physical activity, largely represented by walking, appears to decrease the risk of UI. In cross-sectional analyses, current leisure activity is associated with lower odds of SUI; conversely the lack of exercise increases these odds [51-55]. Similarly, several prospective cohort studies, most notably the Nurses' Health Study, concluded that greater levels of physical activity decreased the risk of developing new UI and also decreased the risk of persistent UI [56-58].

\subsubsection{More UI in Exercisers}

In a comparison of 213 middle-aged women with moderate/ severe SUI and 213 aged-matched women with no/mild SUI, SUI odds increased slightly with overall lifetime activity, but was not associated with lifetime strenuous activity, assessed using the Lifetime Physical Activity Questionnaire [53]. A large body of the literature supports a high prevalence of UI in women participating in sports. Prevalence rates are not directly comparable between studies due to different instruments and definitions of UI and population differences. In previous reviews, the prevalence of reported UI during sports ranged from $28 \%$ in university varsity athletes to $80 \%$ in teenaged nulliparous trampolinists [14-20]. The prevalence is generally greater in high-impact athletes, such as trampolinists, gymnasts, volleyball players, and long-distance runners [15].

All studies [36, 59-65], except $\mathrm{B} \emptyset$ and Borgen [66] and Dockter et al. [67] comparing UI prevalence between athletes and controls report significantly higher prevalence in athletes. For example, Fernandes et al. reported that $63 \%$ of 12-19 year old amateur soccer players demonstrated objective evidence of UI compared to $25 \%$ of similarly aged girls not participating in sports [62]. Systematic reviews have concluded that the odds of UI in athletes/exercising women may be 3.5 times that of controls [17, 18].

There are sparse data on the incidence of UI after initiating exercise or sports training. A prospective study found no difference in the prevalence of SUI before and after a 6 -week program of summer military training completed by 116 young nulliparous women [68].

\subsubsection{UI and PFM Strength in Exercisers}

While exercising women at 37 weeks' gestation had stronger PFM than non-exercising women, the UI prevalence was not different between groups, after adjusting for PFM training, age, pre-pregnancy body mass index, education and smoking [38]. An adjusted linear regression model showed that PFM strength, rather than being a regular exerciser, was associated with continence. In another study, athletes (gymnasts, distance runners and basketball players) had significant higher UI prevalence than sedentary women, despite also having greater PFM strength [36]. Somewhat counter-intuitively, incontinent athletes in a different study had stronger PFM than continent athletes [69].

\subsubsection{Long-Term Effects of Strenuous Exercise on UI}

In a study questioning U.S. Olympians, 20 years after they competed, there were no differences in UI prevalence between a high-impact group (former gymnasts and track and field) and a low-impact group (swimmers) [70]. Similarly, in a 15 year follow-up study, former Norwegian elite athletes, including those participating in high-impact sports, were not more likely to report UI later in life than controls [71]. However, UI early in life was strongly associated with UI at 15 year follow-up. In contrast, in a population of middle-aged women, the predicted probability of SUI rose linearly, though modestly, in those that recalled exceeding $7.5 \mathrm{~h}$ of strenuous activity/week during their teen years, even after adjusting for subsequent strenuous activity during ages 21-65 years [53].

\subsection{What is the Effect of Exercise on Anal Incontinence?}

Few studies were found on exercise and AI. We identified no studies on weight/power lifters, in whom anecdotally AI may be expected, and no long-term studies. 


\subsubsection{Less Al Among Exercisers}

We identified no studies reporting that women exercising have less AI.

\subsubsection{More Al Among Exercisers}

The reported prevalence of AI amongst athletes aged $18-40$ years was $14.8 \%$ in 169 intensive sport athletes compared to $4.9 \%$ in 224 non-intensive women; for the majority, the reported anal incontinence was categorized as flatus [60]. In an Internet survey of 311 female triathletes, $28 \%$ reported anal incontinence [72].

\subsubsection{Evidence Suggesting No Difference in Al Between Exercisers and Controls}

A retrospective study of 40 female athletes and 80 matched controls found that no woman in either group reported fecal incontinence (a subset of anal incontinence, which includes incontinence with flatus or with stool) during pregnancy or several years after pregnancy [73].

\subsection{What is the Effect of Exercise on Pelvic Organ Prolapse?}

There are fewer studies on the relationship between physical activity/exercise and POP than there are for UI.

\subsubsection{Less POP in Exercisers}

No studies were found reporting less POP in exercisers.

\subsubsection{Evidence Suggesting No Difference in POP Between Exercisers and Controls}

In 144 nulliparous women at the United States Military Academy, 50\% had stage I or II POP, which represents mild pelvic floor support deficits, but former and current exercise did not increase odds of POP [74].

Brækken et al. compared 49 women with POP stage $\geq 2$ with 49 women stages $0-1$ and found that BMI, socioeconomic status, heavy occupational work, anal sphincter lacerations and PFM function were independently associated with POP, whereas joint mobility and low intensity physical activity were not [75]. In a cross-sectional analysis of middle-aged women, there were no associations between odds of POP and overall reported lifetime physical activity, lifetime leisure activity, or lifetime strenuous activity between 191 POP cases and 191 age-matched controls [76]. There was a marginally significant nonlinear relationship between teen strenuous activity and POP amongst women reporting $>21 \mathrm{~h} /$ week of teen strenuous activity.

\subsubsection{More POP in Exercisers}

We identified no studies concluding that POP prevalence is higher in exercising than non-exercising women. However, a prospective study of 116 nulliparous female soldiers before and after summer military training concluded that the subset that also did paratrooper training $(n=37)$ were significantly more likely to have stage II POP than those that did only basic training, as well as worsening of their initial pelvic floor support [74].

Compared to findings after overnight bedrest, immediately after $1 \mathrm{~h}$ of structured exercise, more severe POP was found on examination in a group of 54 women planning surgery for POP [77]. One bout of CrossFit exercise increased vaginal descent in another study [35]. In the Internet survey of female triathletes, $5 \%$ endorsed symptoms consistent with POP [72].

\subsection{What Factors Increase the Risk of UI in Exercising Women?}

We identified few consistent factors. In 144 nulliparous, college varsity athletes, there were no significant associations between UI and amenorrhea, weight, hormonal therapy or duration of athletic activity [78]. In former Olympians, only current BMI, but not age, parity or Olympic sport, was associated with regular UI symptoms [70]. Another study of elite athletes found that SUI prevalence was greater in those with an eating disorder, but there were no differences in either menstrual function or BMI between elite athletes with and without SUI [71]. Incontinent trampoliners were older (16 vs 13 years old) and had been training longer and more frequently than those that were continent [79]. A study of 623 athletes from different sports also found that UI prevalence increased with age and long training hours [80].

Compared to continent group fitness instructors, those with UI were older, less likely to use oral contraceptives, and had taught group fitness classes longer [81]. In a population of track and field, basketball and indoor football players, those reporting UI had lower BMI than those that were continent, but there was no difference in age [82]. While $24 \%$ of triathletes in an Internet survey had at least one arm of the female athlete triad (disordered eating, menstrual irregularities, osteoporosis), this was not associated with pelvic floor disorder (PFD) symptoms [72]. Amongst 104 athletes from different sports, only years of training predicted increased risk of evidence of UI based on a pad test [83]. In another study of 50 female athletes, after multivariable adjustment, hours of training per day similarly increased UI odds [84]. 


\subsection{How Does Exercise Affect Labor and Birth?}

\subsubsection{More Difficult Labor and Birth}

We identified no studies reporting that exercising women have more difficult labor and births than non-exercising women.

\subsubsection{Easier Labor and Birth}

A systematic review by the 2016 Evidence summary of the International Olympic Committee expert group meeting on exercise and pregnancy in recreational and elite athletes concluded that exercise did not increase the risk of induction, epidural, episiotomy or perineal tears, and forceps or vacuum delivery, but appeared to be associated with a shorter first stage of labor and lower risk of cesarean delivery [85]. Similarly, a recent systematic review and meta-analysis concluded that based on moderate quality evidence from 20 exercise-only RCTs conducted antenatally $(n=3819)$, the odds of instrumental delivery in women who exercised was lower than those who did not; there were no differences between groups in any other labor/delivery variables studied [86]. However, the conclusions were based on few studies (mostly retrospective and prospective observational studies) and the studies had low-to-moderate quality $[85,86]$.

In a prospective observational study following 274 primiparous women, the levator hiatus area during both rest and valsalva widened during pregnancy [87] and regular exercisers, defined as exercising $\geq 30 \mathrm{~min} \geq 3$ times/week at 37 weeks' gestation had larger, not smaller, levator hiatus area than non-exercisers [88]. There were no differences in delivery outcomes between exercisers and non-exercisers.

In terms of exercise directed at the pelvic floor (pelvic floor muscle training), two observational studies did not find that antenatal PFM training made labor and birth more difficult $[89,90]$. Furthermore, a systematic review including 12 RCTs or quasi RCTs $(n=2243)$ concluded that prenatal PFM training significantly shortened both the first and second stages of labor [91]. The training did not increase the risk of episiotomy, instrumental vaginal delivery or perineal lacerations. However, only three trials with high clinical heterogeneity contributed to the first stage of labor analysis and six trials with high clinical and moderate statistical heterogeneity were pooled in the second stage of labor analysis.

\section{Discussion}

To summarize key findings of this review, exercising women may have similar or stronger PFM and larger levator ani muscles than non-exercising women, but this does not have a greater risk of obstructed labor or childbirth. Women that perform PFM training antenatally also are not more likely to have outcomes associated with obstructed labor (such as prolonged second stage of labor or cesarean delivery), but rather, appear to have shorter first and second stages of labor; this conclusion is limited by lower quality data. In terms of pelvic floor dysfunction, urinary incontinence is common amongst exercising women, with exercise increasing the odds $2.5-3$ times and with greater prevalence rates associated with higher impact activities. Mild-to-moderate physical activity, such as walking, may decrease the risk of future UI. Scant research suggests that strenuous activity in younger women does not predispose to UI in later life, though a large volume of strenuous activity during the teen years might. The few studies available to assess the association between exercise and POP and $\mathrm{AI}$ are inconsistent in their conclusions. The rigor of these findings is limited by inconsistencies in the literature in defining each of the pelvic floor disorders and in methods of assessing and characterizing pelvic floor muscle strength, morphology, and intra-abdominal pressure.

In terms of IAP, variability amongst women is high. Some exercises thought to be associated with higher IAP are in fact not, and many generate lower IAPs than common daily activities. However, whether higher IAPs directly affect the pelvic floor is not known. In addition to the actual load on the pelvic floor, repetitions of loading and dynamic activities may impact the pelvic floor differently than the actual load.

Measuring PFM function during physical activity and specific exercises is very challenging. Results from studies attempting this are difficult to compare. Electromyography (EMG) may provide a means of assessing the kinematic aspects of PFM contraction, and not simply the pressures obtained, during exercise. Whether methods such as surface EMG are valid in assessing PFM activity is debated given input from other muscle groups during multitask activities such as running and jumping [92]. EMG is not a measure of muscle strength, but of activation of muscle fibers. Strength and activation are correlated, but measure different features. Vaginal pressure transducers designed to measure PFM strength may be impacted by IAP increases. Measurement devices to be kept inside the urethra, vagina or rectum during exercise may move, impacting results. Even in the laboratory setting, measuring PFM strength can be challenging. It is vital to ensure that women are indeed contracting the PFM correctly. We are not aware of commercially available instruments that measure increases in IAP and function of the PFM simultaneously, but new developments are being investigated [28, 33]. However, given the location of the PFM inside the pelvis, their close connection to other muscle groups and their inclusion in the abdominal canister that responds to all IAP and 
ground reaction forces, it may prove difficult to differentiate between opposing forces occurring during physical activity.

Studies investigating PFM strength and exercise are cross-sectional, and thus causality cannot be established. That one session of strenuous exercise results in acute PFM fatigue does not provide any evidence about whether such fatigue might cause stronger or weaker PFM in the long term [34]. The effect of IAP on pelvic floor function requires not only consideration of the PFM, but also of other co-existing factors. We suggest that there may be an individual threshold of IAP related to each individual's harm/benefit ratio. Most women can tolerate huge increases in IAP without leaking. Hence, the connective tissue and the PFM are adequately counteracting this increased pressure and corresponding downward movement. In others, only small amounts of IAP may move the pelvic floor downwards [93], widen the levator hiatus [94] and decrease the maximal urethral closure pressure, causing leakage or descent.

Most of the literature about exercise and pelvic floor dysfunction is limited to UI with few studies about AI and POP, and is generalizable to recreational exercisers with scant data about strenuous exercisers and elite athletes. Most large epidemiological studies on physical activity and UI are cross-sectional. The inherent selection bias with this design, especially for a condition like UI, may be large, as women with UI tend to stop exercising. These study designs cannot ascertain whether women are exercising because they are dry or whether they are dry because they exercise. Many epidemiological studies do not control for obesity, which is important as obesity is a risk factor for UI and exercising women are more likely to be within normal weight distribution, thus reducing their risk of UI [11].

Although exercisers may have stronger PFM than nonexercisers, the PFM may still be too weak or too slow to counteract the IAP or ground reaction forces during strenuous activities [21]. It is reasonable for athletes to consider focused strength training of the PFM, particularly if they have symptoms of UI, given the grade A recommendation for PFM training as first line treatment for UI in the general female population [95]. Furthermore, pregnant continent women who exercise the PFM (primary prevention) are $62 \%$ less likely to experience UI in late pregnancy and have a $29 \%$ lower risk of UI 3-6 months postpartum [96]. In women with POP, supervised PFM training results in lift of the pelvic floor, a smaller levator hiatus area and PFM hypertrophy [97].

Whether such training effects are found in elite athletes remains to be investigated. Several small uncontrolled studies suggest that athletes and soldiers demonstrate improvements in symptoms or PFM strength after PFM training [98-100]. In a more recent RCT, in 32 volleyball players, UI was more likely to improve after PFM training than after written information only [101]. However, young, nulliparous women in general, and athletes in particular, have low level of knowledge about the pelvic floor and little knowledge about how to train the PFM [102].

Elite athletes are accustomed to regular training and are highly motivated for exercise. Adding 3 sets of 8-12 close to maximum PFM contractions, 3-4 times a week to their regular strength-training programs is feasible [101, 103]. Proper strength training of the PFM seems to be important as one RCT found that simply contracting the PFM during daily activities does not itself seem to improve PFM function and prevent UI [104]. While a minority of athletes performed a correct PFM contraction at their first assessment in one study, all learned proper technique after individual instruction by a physiotherapist [69]. We are not aware of studies investigating whether exercising women are more likely to adhere to PFM training.

Because most elite athletes are nulliparous, one does not expect damage to ligaments, fascia, muscle fibers or peripheral nerves. Therefore, the effect of PFM training in athletes might be equal to or better than that of other women. On the other hand, the increases in IAP and ground reaction forces that must be counteracted automatically by the athlete's PFM are higher than that required in the general population. The pelvic floor, therefore, probably needs to be much stronger and respond more quickly to forces in elite athletes than in the lay public.

The prevalence of UI during sports is high. Given the numerous health benefits of physical activity, no one should be recommended to stop exercising, and this is certainly not an option for elite athletes. However, athletes should be provided with the same information and advice to train the PFM as the rest of the female population. Athletes do not talk about UI with their coaches or trainers [78, 81, 105]. Education directed at coaches has potential to improve UI in athletes.

\section{Conclusion}

In conclusion, our review identified evidence to support both hypotheses about the effect of physical activity on the pelvic floor. However, data are scant, particularly regarding POP and AI, studies generally cross-sectional, confounders are often not considered, and there is substantial variability in case definitions and assessment methods. These limitations highlight the need for further high-quality research. To enable women to reap the benefits of physical activity without being affected by, or affecting, the pelvic floor, there is an urgent need for a body of research, summarized in Table 3 . There is more support (though still scant) for the hypothesis that strenuous exercise may be a risk factor for PFD, than there is for regular exercise being of benefit for PFM 
function. For women with an optimally functioning pelvic floor, it is likely that physical activity has a positive training effect, through unconscious co-contraction of the PFM, while for those that do not, strenuous exercise may be deleterious. Athletes with an optimally functioning pelvic floor likely demonstrate a continuum of positive and negative

Table 3 Research priorities to understand the associations between physical activity, the pelvic floor, and pelvic floor disorders and the impact of pelvic floor disorders on sports performance and participation

\section{Understudied populations}

Elite athletes

Weight trainers

Pregnant athletes

\section{Understudied outcomes}

Anal incontinence

Pelvic organ prolapse

Labor and delivery: duration of first and second stages, instrumental delivery, cesarean delivery

Under-represented research designs

Prospective cohort studies

Randomized clinical trials

With untreated control groups

Large and generalizable samples

Important research questions

Pelvic floor muscle training

What is the effect of PFMT in recreational athletes on PFD symptoms?

What is the effect of PFMT in women exposed to high loads on the pelvic floor (such as high-impact athletes or weight lifters) on PFD symptoms?

Does the effect of PFMT in athletes on PFD symptoms differ according to type of sport (static versus dynamic)?

Other than PFMT, what treatment modalities may improve PFD symptoms in athletes?

Is PFMT cost effective in athletes?

What is the knowledge base of coaches and trainers about PFM and PFDs?

How can PFMT best be incorporated into athletes' training regimens?

How does PFMT affect athletic performance?

Prospective assessment of effect of exercise on the pelvic floor

How does commencing heavy and strenuous exercise impact the PF?

What is the effect of general exercise training (excluding PFMT) on PFM strength and function?

What is the long-term impact of teen strenuous activity on PFM strength and function, and on PFDs?

What is the long-term impact of strenuous activity initiated after teenaged years on PFM strength and function and PFDs?

Effect of exercise on PFD symptoms

What effect does initiating a sports or exercise training program have on urinary incontinence incidence or resolution?

What are modifiable risk factors for PFDs in elite athletes and strenuous exercisers?

How does UI affect athletic performance?

What beliefs and social constructs do athletes place on UI?

What is the effect of strenuous exercise during pregnancy on subsequent PFD symptoms?

What are the prevalence rates of UI in teenaged athletes performing different types of sports?

Effect of exercise on intra-abdominal pressure

How does exercise training affect IAP during different types of activities?

How does IAP generated during single vs repetitive and static and vs dynamic activities affect PFM strength and function and PFD symptoms?

How does breathing pattern during exercise affect IAP?

\section{Assessment}

How can measuring PFM strength and function accurately during physical activity be improved upon?

How can kinematic aspects of PFM function best be assessed?

What other methods can be developed to measure the influence from physical activity on the pelvic floor?

$P F M$ pelvic floor muscle, $P F M T$ pelvic floor muscle training, $P F D$ pelvic floor disorder, $P F$ pelvic floor, $U I$ urinary incontinence, $I A P$ intraabdominal pressure 
responses to impact; e.g., a gymnast may have a pelvic floor that can withstand the forces generated from landing on the floor exercise mat, but may leak during landing on the beam. The threshold for optimal or negative effects on the pelvic floor almost certainly differs from person to person.

\section{Compliance with Ethical Standards}

Funding This work was supported in part by Grant number 1P01HD080629 (Ingrid Nygaard) from the Eunice Kennedy Shriver National Institute of Child Health and Human Development. Its content is solely the responsibility of the authors and does not necessarily represent the official views of the National Institutes of Health. The sponsor played no role in the collection, analysis and interpretation of the data or the writing of the manuscript.

Conflict of Interest Kari Bo and Ingrid Nygaard declare that they have no conflicts of interest relevant to the content of this review.

Open Access This article is licensed under a Creative Commons Attribution 4.0 International License, which permits use, sharing, adaptation, distribution and reproduction in any medium or format, as long as you give appropriate credit to the original author(s) and the source, provide a link to the Creative Commons licence, and indicate if changes were made. The images or other third party material in this article are included in the article's Creative Commons licence, unless indicated otherwise in a credit line to the material. If material is not included in the article's Creative Commons licence and your intended use is not permitted by statutory regulation or exceeds the permitted use, you will need to obtain permission directly from the copyright holder. To view a copy of this licence, visit http://creativecommons.org/licenses/by/4.0/.

\section{References}

1. Bouchard C, Shephard R, Stephens T. Physical activity, fitness and health. Consensus statement. Champagne: Human Kinetics Publishers; 1993.

2. Pedersen BK, Saltin B. Exercise as medicine-evidence for prescribing exercise as therapy in 26 different chronic diseases. Scand J Med Sci Sports. 2015;25(Suppl 3):1-72.

3. Physical Activity Guidelines Advisory Committee I. 2018. Physical Activity Guidelines Advisory Committee scientific report. Washington: U.S. Department of Health and Human Services; 2018.

4. Bump RC, Norton PA. Epidemiology and natural history of pelvic floor dysfunction. Obstet Gynecol Clin N Am. 1998;25(4):723-46.

5. Nygaard I, Barber MD, Burgio KL, Kenton K, Meikle S, Schaffer $\mathrm{J}$, et al. Prevalence of symptomatic pelvic floor disorders in US women. JAMA. 2008;300(11):1311-6.

6. Gyhagen M, Akervall S, Milsom I. Clustering of pelvic floor disorders 20 years after one vaginal or one cesarean birth. Int Urogynecol J. 2015;26(8):1115-21.

7. Brown WJ, Miller YD. Too wet to exercise? Leaking urine as a barrier to physical activity in women. J Sci Med Sport. 2001;4(4):373-8.

8. Nygaard I, Girts T, Fultz NH, Kinchen K, Pohl G, Sternfeld B. Is urinary incontinence a barrier to exercise in women? Obstet Gynecol. 2005;106(2):307-14.
9. Subak LL, Brown JS, Kraus SR, Brubaker L, Lin F, Richter HE, et al. The "costs" of urinary incontinence for women. Obstet Gynecol. 2006;107(4):908-16.

10. Ding D, Lawson KD, Kolbe-Alexander TL, Finkelstein EA, Katzmarzyk PT, van Mechelen W, et al. The economic burden of physical inactivity: a global analysis of major non-communicable diseases. Lancet. 2016;388(10051):1311-24.

11. Milsom I, Altman D, Cartwright R, Lapitan M, Nelson R, Sjöström S, et al. Epidemiology of urinary incontinence [UI] andother lower urinary tract symptoms [LUTS], pelvic organ prolapse [POP] and anal [AI] incontinence. In: Abrams P, Wagg A, Wein A, editors. Incontinence. Tokyo: 6th international consultation on incontinence; 2017.

12. Haylen BT, de Ridder D, Freeman RM, Swift SE, Berghmans $\mathrm{B}$, Lee J, et al. An International Urogynecological Association [IUGA]/International Continence Society [ICS] joint report on the terminology for female pelvic floor dysfunction. Neurourol Urodyn. 2010;29(1):4-20.

13. $\mathrm{B} \emptyset \mathrm{K}$. Urinary incontinence, pelvic floor dysfunction, exercise and sport. Sports Med. 2004;34(7):451-64.

14. Goldstick O, Constantini N. Urinary incontinence in physically active women and female athletes. Br J Sports Med. 2014;48(4):296-8.

15. Nygaard IE, Shaw JM. Physical activity and the pelvic floor. Am J Obstet Gynecol. 2016;214(2):164-71.

16. Shaw JM, Nygaard IE. Role of chronic exercise on pelvic floor support and function. Curr Opin Urol. 2017;27(3):257-61.

17. Teixeira RV, Colla C, Sbruzzi G, Mallmann A, Paiva LL. Prevalence of urinary incontinence in female athletes: a systematic review with meta-analysis. Int Urogynecol J. 2018;29(12):1717-25.

18. de Mattos Lourenco TR, Matsuoka PK, Baracat EC, Haddad JM. Urinary incontinence in female athletes: a systematic review. Int Urogynecol J. 2018;29(12):1757-63.

19. Opara JST, Bidzan M, Mehlich KPA. Stress urine incontinence especially in elite women athletes extremely practicing sports. Arch Budo Sci Martial Arts. 2011;7:227-31.

20. $\mathrm{B} \varnothing \mathrm{K}$. Pelvic floor dysfunction, prevention and treatment in elite athletes. In: B $\varnothing$ K, Berghmans B, Mørkved S, van Kampen M, editors. Evidence based physical therapy for the pelvic floor bridging science and clinical practice. London: Churchill Livingstone; 2015. p. 397-407.

21. Constantinou CE, Govan DE. Spatial distribution and timing of transmitted and reflexly generated urethral pressures in healthy women. J Urol. 1982;127(5):964-9.

22. Miller JM, Ashton-Miller JA, DeLancey JO. A pelvic muscle precontraction can reduce cough-related urine loss in selected women with mild SUI. J Am Geriatr Soc. 1998;46(7):870-4.

23. Hay JG. Citius, altius, longius [faster, higher, longer]: the biomechanics of jumping for distance. J Biomech. 1993;26(Suppl 1):7-21.

24. Seegmiller JG, McCaw ST. Ground reaction forces among gymnasts and recreational athletes in drop landings. J Athl Train. 2003;38(4):311-4.

25. James ED. The behaviour of the bladder during physical activity. Br J Urol. 1978;50(6):387-94.

26. Nygaard IE, Hamad NM, Shaw JM. Activity restrictions after gynecologic surgery: is there evidence? Int Urogynecol J. 2013;24(5):719-24.

27. Hamad NM, Shaw JM, Nygaard IE, Coleman TJ, Hsu Y, Egger M, et al. More complicated than it looks: the vagaries of calculating intra-abdominal pressure. J Strength Cond Res. 2013;27:3201-15.

28. Arora AS, Kruger JA, Budgett DM, Hayward LM, Smalldridge J, Nielsen PF, et al. Clinical evaluation of a high-fidelity 
wireless intravaginal pressure sensor. Int Urogynecol J. 2015;26(2):243-9.

29. Hagins M, Pietrek M, Sheikhzadeh A, Nordin M, Axen K. The effects of breath control on intra-abdominal pressure during lifting tasks. Spine (Phila Pa 1976). 2004;29(4):464-9.

30. Tian T, Budgett S, Smalldridge J, Hayward L, Stinear J, Kruger $\mathrm{J}$. Assessing exercises recommended for women at risk of pelvic floor disorders using multivariate statistical techniques. Int Urogynecol J. 2018;29(10):1447-54.

31. Weir LF, Nygaard IE, Wilken J, Brandt D, Janz KF. Postoperative activity restrictions: any evidence? Obstet Gynecol. 2006;107(2 Pt 1):305-9.

32. Yamasato KS, Oyama IA, Kaneshiro B. Intraabdominal pressure with pelvic floor dysfunction: do postoperative restrictions make sense? J Reprod Med. 2014;59(7-8):409-13.

33. Kruger J, Budgett $\mathrm{D}$, Goodman J, Bø K. Can you train the pelvic floor muscles by contracting other related muscles? Neurourol Urodyn. 2019;38(2):677-83.

34. Ree ML, Nygaard I, Bo K. Muscular fatigue in the pelvic floor muscles after strenuous physical activity. Acta Obstet Gynecol Scand. 2007;86(7):870-6.

35. Middlekauff ML, Egger MJ, Nygaard IE, Shaw JM. The impact of acute and chronic strenuous exercise on pelvic floor muscle strength and support in nulliparous healthy women. Am J Obstet Gynecol. 2016;215(3):316.e1-7.

36. de Araujo M, Parmigiano T, Della Negra L, Torelli L, de Carvalho $\mathrm{C}$, Wo $\mathrm{L}$, et al. Evaluation of athletes' pelvic floor: is there a relation with urinary incontinence? Rev Bras Med Esporte. 2015;21:442-6.

37. Jürgensen SP, Borghi-Silva A, Bastos AMFG, Correia GN, Pereira-Baldon VS, Cabiddu R, et al. Relationship between aerobic capacity and pelvic floor muscles function: a cross-sectional study. Braz J Med Biol Res. 2017;50(11):e5996.

38. Bø K, Ellstrøm Engh M, Hilde G. Regular exercisers have stronger pelvic floor muscles than nonregular exercisers at midpregnancy. Am J Obstet Gynecol. 2018;218(4):427.e1-5.

39. Borin LC, Nunes FR, Guirro EC. Assessment of pelvic floor muscle pressure in female athletes. PM R. 2013;5(3):189-93.

40. Varella LR, Torres VB, Angelo PH, Eugênia de Oliveira MC, Matias de Barros AC, Viana EeS, et al. Influence of parity, type of delivery, and physical activity level on pelvic floor muscles in postmenopausal women. J Phys Ther Sci. 2016;28(3):824-30.

41. Ferla L, Paiva LL, Darki C, Vieira A. Comparison of the functionality of pelvic floor muscles in women who practice the Pilates method and sedentary women: a pilot study. Int Urogynecol J. 2016;27(1):123-8.

42. Moss W, Shaw JM, Yang M, Sheng X, Hitchcock R, Niederauer $\mathrm{S}$, et al. The association between pelvic floor muscle force and general strength and fitness in postpartum women. Female Pelvic Med Reconstr Surg. 2019. https://doi.org/10.1097/SPV.00000 00000000718.

43. Carvalhais A, Da Roza T, Vilela S, Jorge RN, Bø K. Association between physical activity level and pelvic floor muscle variables in women. Int J Sports Med. 2018;39(13):995-1000.

44. Luginbuehl H, Naeff R, Zahnd A, Baeyens JP, Kuhn A, Radlinger L. Pelvic floor muscle electromyography during different running speeds: an exploratory and reliability study. Arch Gynecol Obstet. 2016;293(1):117-24.

45. Saeuberli PW, Schraknepper A, Eichelberger P, Luginbuehl H, Radlinger L. Reflex activity of pelvic floor muscles during drop landings and mini-trampolining-exploratory study. Int Urogynecol J. 2018;29(12):1833-40.

46. Moser H, Leitner M, Baeyens JP, Radlinger L. Pelvic floor muscle activity during impact activities in continent and incontinent women: a systematic review. Int Urogynecol J. 2018;29(2):179-96.
47. Kruger JA, Murphy BA, Heap SW. Alterations in levator ani morphology in elite nulliparous athletes: a pilot study. Aust N Z J Obstet Gynaecol. 2005;45(1):42-7.

48. Kruger JA, Dietz HP, Murphy BA. Pelvic floor function in elite nulliparous athletes. Ultrasound Obstet Gynecol. 2007;30(1):81-5.

49. Roza TD, Brandão S, Oliveira D, Mascarenhas T, Parente M, Duarte JA, et al. Football practice and urinary incontinence: relation between morphology, function and biomechanics. J Biomech. 2015;48(9):1587-92.

50. Barton A, Serrao C, Thompson J, Briffa K. Transabdominal ultrasound to assess pelvic floor muscle performance during abdominal curl in exercising women. Int Urogynecol J. 2015;26(12):1789-95.

51. Hannestad YS, Rortveit G, Daltveit AK, Hunskaar S. Are smoking and other lifestyle factors associated with female urinary incontinence? The Norwegian EPINCONT Study. BJOG. 2003;110(3):247-54.

52. Zhu L, Lang J, Wang H, Han S, Huang J. The prevalence of and potential risk factors for female urinary incontinence in Beijing, China. Menopause. 2008;15(3):566-9.

53. Nygaard IE, Shaw JM, Bardsley T, Egger MJ. Lifetime physical activity and female stress urinary incontinence. Am J Obstet Gynecol. 2015;213(1):40.e1-10.

54. Lee AH, Hirayama F. Physical activity and urinary incontinence in older adults: a community-based study. Curr Aging Sci. 2012;5(1):35-40.

55. Qiu J, Lv L, Lin X, Long L, Zhu D, Xu R, et al. Body mass index, recreational physical activity and female urinary incontinence in Gansu, China. Eur J Obstet Gynecol Reprod Biol. 2011;159(1):224-9.

56. Townsend MK, Danforth KN, Rosner B, Curhan GC, Resnick NM, Grodstein F. Physical activity and incident urinary incontinence in middle-aged women. J Urol. 2008;179(3):1012-6 (discussion 6-7).

57. Devore EE, Minassian VA, Grodstein F. Factors associated with persistent urinary incontinence. Am J Obstet Gynecol. 2013;209(2):145.e1-6.

58. Morrisroe SN, Rodriguez LV, Wang PC, Smith AL, Trejo L, Sarkisian CA. Correlates of 1-year incidence of urinary incontinence in older Latino adults enrolled in a community-based physical activity trial. J Am Geriatr Soc. 2014;62(4):740-6.

59. Caylet N, Fabbro-Peray P, Marès P, Dauzat M, Prat-Pradal D, Corcos J. Prevalence and occurrence of stress urinary incontinence in elite women athletes. Can J Urol. 2006;13(4):3174-9.

60. Vitton V, Baumstarck-Barrau K, Brardjanian S, Caballe I, Bouvier M, Grimaud JC. Impact of high-level sport practice on anal incontinence in a healthy young female population. J Womens Health (Larchmt). 2011;20(5):757-63.

61. Fozzatti C, Riccetto C, Herrmann V, Brancalion MF, Raimondi $\mathrm{M}$, Nascif $\mathrm{CH}$, et al. Prevalence study of stress urinary incontinence in women who perform high-impact exercises. Int Urogynecol J. 2012;23(12):1687-91.

62. Fernandes A, Fitz F, Silva A, Filoni E, Filho JM. 0016 Evaluation of the prevalence of urinary incontinence symptoms in adolescent female soccer players and their impact on quality of life. Occup Environ Med. 2014;71(Suppl 1):A59-60.

63. Hagovska M, Svihra J, Bukova A, Horbacz A, Svihrova V. The impact of physical activity measured by the International Physical Activity questionnaire on the prevalence of stress urinary incontinence in young women. Eur J Obstet Gynecol Reprod Biol. 2018;228:308-12.

64. Bø K, Hagen R, Kvarstein B, Larsen S. Female stress urinary incontinence and participation in different sports and social activities. Scand J Sports Sci. 1989;11:117-21. 
65. Figueres C, Boyle K, Caprio K, Weidner A. Pelvic floor muscle activity and urinary incontinence in weight-bearing female athletes vs non-athletes. J Women's Health Phys Ther. 2008;32:7-11.

66. Bo K, Borgen JS. Prevalence of stress and urge urinary incontinence in elite athletes and controls. Med Sci Sports Exerc. 2001;33(11):1797-802.

67. Dockter M, Kolstad A, Martin K, Schiwal L. Prevalence of urinary incontinence: a comparative study of collegiate female athletes and non-athletic controls. J Women's Health Phys Ther. 2007;31:12-7.

68. Larsen WI, Yavorek T. Pelvic prolapse and urinary incontinence in nulliparous college women in relation to paratrooper training. Int Urogynecol J Pelvic Floor Dysfunct. 2007;18(7):769-71.

69. Dos Santos KM, Da Roza T, Mochizuki L, Arbieto ERM, TonondaLuz SC. Assessment of abdominal and pelvic floor muscle function among continent and incontinent athletes. Int Urogynecol J. 2019;30(5):693-9.

70. Nygaard IE. Does prolonged high-impact activity contribute to later urinary incontinence? A retrospective cohort study of female Olympians. Obstet Gynecol. 1997;90(5):718-22.

71. Bo K, Sundgot-Borgen J. Are former female elite athletes more likely to experience urinary incontinence later in life than nonathletes? Scand J Med Sci Sports. 2010;20(1):100-4.

72. Yi J, Tenfelde S, Tell D, Brincat C, Fitzgerald C. Triathlete risk of pelvic floor disorders, pelvic girdle pain, and female athlete triad. Female Pelvic Med Reconstr Surg. 2016;22(5):373-6.

73. Bo K, Backe-Hansen KL. Do elite athletes experience low back, pelvic girdle and pelvic floor complaints during and after pregnancy? Scand J Med Sci Sports. 2007;17(5):480-7.

74. Larsen WI, Yavorek TA. Pelvic organ prolapse and urinary incontinence in nulliparous women at the United States Military Academy. Int Urogynecol J Pelvic Floor Dysfunct. 2006;17(3):208-10.

75. Braekken IH, Majida M, Ellström Engh M, Holme IM, B $\varnothing$ K. Pelvic floor function is independently associated with pelvic organ prolapse. BJOG. 2009;116(13):1706-14.

76. Nygaard IE, Shaw JM, Bardsley T, Egger MJ. Lifetime physical activity and pelvic organ prolapse in middle-aged women. Am J Obstet Gynecol. 2014;210(5):477.e1-12.

77. Ali-Ross NS, Smith AR, Hosker G. The effect of physical activity on pelvic organ prolapse. BJOG. 2009;116(6):824-8.

78. Nygaard IE, Thompson FL, Svengalis SL, Albright JP. Urinary incontinence in elite nulliparous athletes. Obstet Gynecol. 1994;84(2):183-7.

79. Eliasson K, Larsson T, Mattsson E. Prevalence of stress incontinence in nulliparous elite trampolinists. Scand J Med Sci Sports. 2002;12(2):106-10.

80. Simeone C, Moroni A, Pettenò A, Antonelli A, Zani D, Orizio $\mathrm{C}$, et al. Occurrence rates and predictors of lower urinary tract symptoms and incontinence in female athletes. Urologia. 2010;77(2):139-46.

81. Bo K, Bratland-Sanda S, Sundgot-Borgen J. Urinary incontinence among group fitness instructors including yoga and Pilates teachers. Neurourol Urodyn. 2011;30(3):370-3.

82. Jácome C, Oliveira D, Marques A, Sá-Couto P. Prevalence and impact of urinary incontinence among female athletes. Int $\mathbf{J}$ Gynaecol Obstet. 2011;114(1):60-3.

83. Dos Santos KM, Da Roza T, Tonon da Luz SC, Hort JP, Kruger JM, Schevchenco B. Quantification of urinary loss in nulliparous athletes during 1 hour of sports training. PM R. 2019;11(5):495-502.

84. Dos Santos KM, Da Roza T, da Silva LL, Wolpe RE, da Silva Honório GJ, Tonon da Luz SC. Female sexual function and urinary incontinence in nulliparous athletes: an exploratory study. Phys Ther Sport. 2018;33:21-6.

85. B $\varnothing \mathrm{K}$, Artal R, Barakat R, Brown W, Dooley M, Evenson KR, et al. Exercise and pregnancy in recreational and elite athletes: 2016 evidence summary from the IOC expert group meeting, Lausanne. Part 2-The effect of exercise on the fetus, labour and birth. Br J Sports Med. 2016;50(21):1297-305.

86. Davenport MH, Ruchat SM, Sobierajski F, Poitras VJ, Gray $\mathrm{CE}$, Yoo $\mathrm{C}$, et al. Impact of prenatal exercise on maternal harms, labour and delivery outcomes: a systematic review and meta-analysis. Br J Sports Med. 2019;53(2):99-107.

87. Stær-Jensen J, Siafarikas F, Hilde G, Bø K, Engh ME. Ultrasonographic evaluation of pelvic organ support during pregnancy. Obstet Gynecol. 2013;122(2 Pt 1):329-36.

88. Bø K, Hilde G, Staer-Jensen J, Siafarikas F, Tennfjord MK, Engh ME. Does general exercise training before and during pregnancy influence the pelvic floor "opening" and delivery outcome? A 3D/4D ultrasound study following nulliparous pregnant women from mid-pregnancy to childbirth. Br J Sports Med. 2015;49(3):196-9.

89. B $\varnothing \mathrm{K}$, Fleten $\mathrm{C}$, Nystad W. Effect of antenatal pelvic floor muscle training on labor and birth. Obstet Gynecol. 2009;113(6):1279-84.

90. B $\emptyset$ K, Hilde G, Jensen JS, Siafarikas F, Engh ME. Too tight to give birth? Assessment of pelvic floor muscle function in 277 nulliparous pregnant women. Int Urogynecol J. 2013;24(12):2065-70.

91. Du Y, Xu L, Ding L, Wang Y, Wang Z. The effect of antenatal pelvic floor muscle training on labor and delivery outcomes: a systematic review with meta-analysis. Int Urogynecol J. 2015;26(10):1415-27.

92. В $\varnothing$ K, Sherburn M. Evaluation of female pelvic-floor muscle function and strength. Phys Ther. 2005;85(3):269-82.

93. Bø K, Sherburn M, Allen T. Transabdominal ultrasound measurement of pelvic floor muscle activity when activated directly or via a transversus abdominis muscle contraction. Neurourol Urodyn. 2003;22(6):582-8.

94. Bø K, Braekken IH, Majida M, Engh ME. Constriction of the levator hiatus during instruction of pelvic floor or transversus abdominis contraction: a 4D ultrasound study. Int Urogynecol J Pelvic Floor Dysfunct. 2009;20(1):27-32.

95. Dumoulin C, Cacciari LP, Hay-Smith EJC. Pelvic floor muscle training versus no treatment, or inactive control treatments, for urinary incontinence in women. Cochrane Database Syst Rev. 2018;10:CD005654.

96. Woodley SJ, Boyle R, Cody JD, Mørkved S, Hay-Smith EJC. Pelvic floor muscle training for prevention and treatment of urinary and faecal incontinence in antenatal and postnatal women. Cochrane Database Syst Rev. 2017;12:CD007471.

97. Braekken IH, Hoff Braekken I, Majida M, Engh ME, Bø K. Morphological changes after pelvic floor muscle training measured by 3-dimensional ultrasonography: a randomized controlled trial. Obstet Gynecol. 2010;115(2 Pt 1):317-24.

98. Da Roza T, de Araujo MP, Viana R, Viana S, Jorge RN, Bo $\mathrm{K}$, et al. Pelvic floor muscle training to improve urinary incontinence in young, nulliparous sport students: a pilot study. Int Urogynecol J. 2012;23:1069-73.

99. Rivalta M, Sighinolfi MC, Micali S, De Stefani S, Torcasio F, Bianchi G. Urinary incontinence and sport: first and preliminary experience with a combined pelvic floor rehabilitation program in three female athletes. Health Care Women Int. 2010;31(5):435-43.

100. Sherman RA, Davis GD, Wong MF. Behavioral treatment of exercise-induced urinary incontinence among female soldiers. Mil Med. 1997;162(10):690-4. 
101. Ferreira S, Ferreira M, Carvalhais A, Santos P, Rocha P, Brochado G. Reeducation of pelvic floor muscles in volleyball athletes. Rev Assoc Med Bras. 2014;60:428-33.

102. Cardoso AMB, Lima CROP, Ferreira CWS. Prevalence of urinary incontinence in high-impact sports athletes and their association with knowledge, attitude and practice about this dysfunction. Eur J Sport Sci. 2018;18(10):1405-12.

103. Garber CE, Blissmer B, Deschenes MR, Franklin BA, Lamonte MJ, Lee IM, et al. American College of Sports Medicine position stand. Quantity and quality of exercise for developing and maintaining cardiorespiratory, musculoskeletal, and neuromotor fitness in apparently healthy adults: guidance for prescribing exercise. Med Sci Sports Exerc. 2011;43(7):1334-59.

104. de Andrade RL, Bø K, Antonio FI, Driusso P, Mateus-Vasconcelos ECL, Ramos S, et al. An education program about pelvic floor muscles improved women's knowledge but not pelvic floor muscle function, urinary incontinence or sexual function: a randomised trial. J Physiother. 2018;64(2):91-6.

105. Thyssen HH, Clevin L, Olesen S, Lose G. Urinary incontinence in elite female athletes and dancers. Int Urogynecol J Pelvic Floor Dysfunct. 2002;13(1):15-7.

106. O'Dell KK, Morse AN, Crawford SL, Howard A. Vaginal pressure during lifting, floor exercises, jogging, and use of hydraulic exercise machines. Int Urogynecol J Pelvic Floor Dysfunct. 2007;18(12):1481-9.

107. Kruger J, Hayward L, Nielsen P, Loiselle D, Kirton R. Design and development of a novel intra-vaginal pressure sensor. Int Urogynecol J. 2013;24(10):1715-21.

108. Shaw JM, Hamad NM, Coleman TJ, Egger MJ, Hsu Y, Hitchcock $\mathrm{R}$, et al. Intra-abdominal pressures during activity in women using an intra-vaginal pressure transducer. J Sports Sci. 2014;32(12):1176-85.

109. Coleman TJ, Hamad NM, Shaw JM, Egger MJ, Hsu Y, Hitchcock R, et al. Effects of walking speeds and carrying techniques on intra-abdominal pressure in women. Int Urogynecol J. 2015;26(7):967-74.

110. Simpson S, Deeble M, Thompson J, Andrews A, Briffa K. Should women with incontinence and prolapse do abdominal curls? Int Urogynecol J. 2016;27(10):1507-12.

111. de Gennaro JD, de Gennaro CK, Shaw JM, Petelenz TJ, Nygaard IE, Hitchcock RW. The relationship between intra-abdominal pressure and body acceleration during exercise. Female Pelvic Med Reconstr Surg. 2019;25(3):231-7.

112. Mouritsen L, Hulbaek M, Brostrøm S, Bogstad J. Vaginal pressure during daily activities before and after vaginal repair. Int Urogynecol J Pelvic Floor Dysfunct. 2007;18(8):943-8.

113. Gerten KA, Richter HE, Wheeler TL 2nd, Pair LS, Burgio KL, Redden DT, et al. Intraabdominal pressure changes associated with lifting: implications for postoperative activity restrictions. Am J Obstet Gynecol. 2008;198(3):306 e1-5.

114. Coleman TJ, Nygaard IE, Holder DN, Egger MJ, Hitchcock RW. Intra-abdominal pressure during Pilates: unlikely to cause pelvic floor harm. Int Urogynecol J. 2015;26:1123-30.

115. Hsu Y, Hitchcock R, Niederauer S, Nygaard IE, Shaw JM, Sheng $\mathrm{X}$. Variables affecting intra-abdominal pressure during lifting in the early postpartum period. Female Pelvic Med Reconstr Surg. 2018;24:287-91. 